
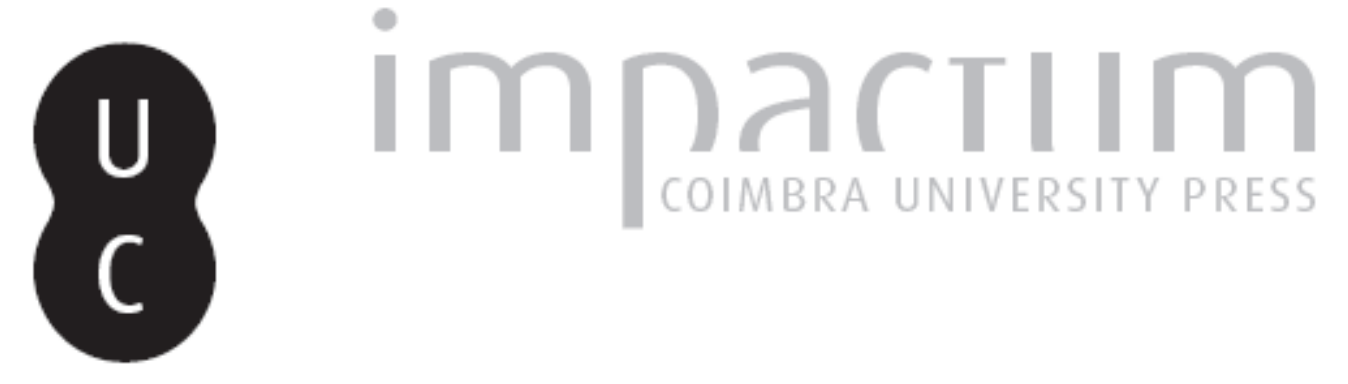

\title{
Contributos para o estudo sobre a feminização do jornalismo português
}

Autor(es): $\quad$ Miranda, João

Publicado por: Imprensa da Universidade de Coimbra

URL persistente:

URI:http://hdl.handle.net/10316.2/42810

DOI: $\quad$ DOI:https://doi.org/10.14195/2183-5462_30_2

Accessed : $\quad$ 26-Apr-2023 13:07:18

A navegação consulta e descarregamento dos títulos inseridos nas Bibliotecas Digitais UC Digitalis, UC Pombalina e UC Impactum, pressupõem a aceitação plena e sem reservas dos Termos e Condições de Uso destas Bibliotecas Digitais, disponíveis em https://digitalis.uc.pt/pt-pt/termos.

Conforme exposto nos referidos Termos e Condições de Uso, o descarregamento de títulos de acesso restrito requer uma licença válida de autorização devendo o utilizador aceder ao(s) documento(s) a partir de um endereço de IP da instituição detentora da supramencionada licença.

Ao utilizador é apenas permitido o descarregamento para uso pessoal, pelo que o emprego do(s) título(s) descarregado(s) para outro fim, designadamente comercial, carece de autorização do respetivo autor ou editor da obra.

Na medida em que todas as obras da UC Digitalis se encontram protegidas pelo Código do Direito de Autor e Direitos Conexos e demais legislação aplicável, toda a cópia, parcial ou total, deste documento, nos casos em que é legalmente admitida, deverá conter ou fazer-se acompanhar por este aviso.

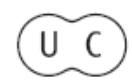


Media Jornalismo Imprensa da Universidade de Coimbra / Coimbra University Press 2 N. 30 Vol. 17, N. . 1 - 2017

\section{MULHERES E MEDIA}




\title{
CONTRIBUTOS PARA O ESTUDO SOBRE A FEMINIZAÇÃO DO JORNALISMO PORTUGUÊS ${ }^{1}$
}

\author{
CONTRIBUTION TO THE STUDY OF PORTUGUESE \\ JOURNALISM'S FEMINIZATION
}

\begin{abstract}
JOÃO MIRANDA
Universidade de Coimbra, Faculdade de Letras, Centro de Estudos Interdisciplinares do Século XX, 3004-530 Coimbra, Portugal
\end{abstract}

jaoamsantosmiranda@gmail.com

\begin{abstract}
Resumo
Com base nos dados da comissão da carteira profissional e nos resultados de um inquérito nacional aos jornalistas, o presente estudo procura oferecer alguns contributos empíricos para um enquadramento da atualidade do processo de feminização das redações portuguesas, fundamentando-se em duas premissas gerais: um trajeto de recomposição sociográfica do jornalismo português, no sentido da contração das disparidades de género - alicerçado em fatores como o rejuvenescimento da profissão e o aumento da formação dos jornalistas -, e um quadro de contradições desse mesmo processo de feminização - onde se destaca a falta de representação das mulheres nos cargos e funções de responsabilidade editorial, e uma desestruturação das condições laborais. A desagregação por género dos resultados do inquérito demonstra que, não obstante uma tendência geral para uma relativa harmonia entre as respostas de homens e mulheres, se evidenciam algumas discrepâncias relativas à situação laboral e ao campo das conceções sobre o exercício da profissão.
\end{abstract}

\section{Palavras-chave \\ Jornalistas; Feminização; Profissão; Género}

\section{Abstract}

Based on data from the Professional Journalist Commission and the results of a national survey of journalists, the present study seeks to offer some empirical contributions to the current framework of the feminization process of Portuguese newsrooms, based on two general premises: a sociological recomposition of Portuguese journalism towards a reduction of gender disparities - based on factors such as the rejuvenation of the profession and the increase in the training of journalists - and a picture of contradictions of the very same process of feminization - highlighting the lack of representation of women in positions and roles of editorial responsibility, and a disruption of their working conditions. The gender breakdown of the survey results shows that, despite a general trend towards a relative harmony between

1 Este trabalho é enquadrado pela Fundação para a Ciência e a Tecnologia (FCT) através da bolsa de doutoramento FCT SFRH/BD/87020/2012 
the responses of men and women, some discrepancies concerning the employment situation and the field of conceptions on the exercise of the profession are evident.

\author{
KEYWORDS \\ Journalists; Feminization; Profession; Gender
}

\title{
INTRODUÇ̃̃o
}

Quando, no segundo dia do $4^{\circ}$ Congresso dos Jornalistas Portugueses, terminou a mesa-redonda que juntou 19 diretores de informação, já as redes sociais estavam ocupadas pelo mais diverso tipo de reflexões sobre o debate. Entre as críticas à incapacidade do reconhecimento, por parte dos responsáveis, da precariedade no jornalismo e pareceres sobre os próprios diretores, emergia um argumento distinto, alicerçado na moldura cénica composta por uma vintena de responsáveis editoriais sentados, num palco, de forma perfeitamente alinhada. Sob a égide de tópicos como "mulher não entra", diferentes internautas confluíam numa mesma interrogação: como era possível, naquele grupo de quase vinte pessoas, apenas se acharem duas mulheres?

Esta linha de argumento - que, de resto, havia já sido levantada relativamente ao próprio quadro de oradores do congresso (66 homens e 18 mulheres) ${ }^{2}$ - compreende, porém, um contexto bastante mais complexo do que a organização do evento: ela reflete ausência de mulheres nas esferas da decisão do jornalismo português.

A questão suscitada no congresso é um dos aspetos que baseia o presente artigo, 0 qual procura oferecer alguns contributos empíricos para um enquadramento da atualidade do processo de feminização das redações portuguesas, fundamentando-se em duas premissas gerais. A primeira debate-se com um trajeto de recomposição sociográfica do jornalismo português, no sentido da contração das disparidades de género - alicerçado em fatores como o rejuvenescimento da profissão e o aumento da formação dos jornalistas. A segunda reporta-se a um quadro de inconsistências desse mesmo processo de feminização - onde se destaca a falta de representação das mulheres nos cargos e funções de responsabilidade editorial, e uma desestruturação das condições laborais. Ao mesmo tempo, a partir da dessegregação por género dos resultados de um inquérito nacional aos jornalistas, procura-se entender a correspondência prática entre estes aspetos e a realidade das procedimentos, condições e expetativas dos profissionais.

\section{O PROCESSO DE FEMINIZAÇÃO DO JORNALISMO PORTUGUÊS}

Não obstante a atual conjuntura sistémica do jornalismo tender a desacelerar, ou mesmo inverter, essas dinâmicas, o trajeto de recomposição do contexto profissional do jornalismo português tem-se desenvolvido, no período pós-transição democrática, na esteira de uma série de tendências de reconfiguração sociográfica relativamente constantes e interdependentes. Dentro deste quadro assumem particular relevância as dinâmicas de permanente rejuvenescimento da profissão - progressivamente mitiga-

2 Veja-se sobre isto, a título de exemplo, a entrada no Tumblr do movimento \#mulhernãoentra - http:// mulhernaoentra.tumblr.com/post/155804715253/4º-congresso-dos-jornalistas-portugueses-1201-a 
das por um contexto de esvaziamento das redações ${ }^{3}$ - e, decorrentes disto, contínuos processos de feminização e aumento da qualificação dos jornalistas (Garcia, 2009).

Com efeito, um dos motores de reconfiguração do jornalismo teve como base este contexto de constante renovação da profissão, pautado sobretudo por ocasionais movimentos de ingresso profissional, articulados com um abandono precoce relativamente transversal. Este contexto, aliado a um quadro generalizado do acesso das mulheres ao profissionalismo, bem como uma composição eminentemente feminina do conjunto de novos licenciados nas áreas da comunicação, conduziu a uma progressiva contração ou mesmo contraversão da disparidade de género nas redações e no acesso à profissão.

Conquanto se identifique hoje um abrandamento do processo de rejuvenescimento do corpo profissional, os dados disponibilizados pela Comissão da Carteira Profissional de Jornalista (CCPJ) revelam um quadro etário da profissão ainda relativamente jovem, onde a maioria dos jornalistas ${ }^{4}$ se enquadra nos estratos abaixo dos 50 anos de idade, e onde 42,3 por cento possui menos de 40 anos - uma fração ainda assim distante dos 57,3 por cento de 2006 (Rebelo et al., 2011). Aliás, compreendendo apenas os detentores do título profissional, verifica-se uma variação de menos 12,9 por cento entre o número de jornalistas com menos de 40 anos em 2006 e 2016.

Não obstante o paradigma de estreitamento do segmento dos jornalistas com menos de 40 anos, continua a ser entre os setores mais jovens da profissão onde, como referiam então relativamente aos dados de 2006 Rebelo et al. (2011), se evidencia uma vaga de feminização do jornalismo e uma tendência para a recomposição de género nas redações. Segundo os dados de 2014, as mulheres compunham 53,9 por cento do total de profissionais com menos de 40 anos.

Ainda sobre a questão da redução do contingente de jornalistas e os seus efeitos sobre os processos de feminização, interessará observar que este fenómeno assume uma relativa similitude entre géneros: uma comparação entre 0 total de titulares de Carteira Profissional de Jornalista em 2004 e 2014 demonstra uma diminuição de 18,5 por cento de homens e 17 por cento de mulheres.

Um segundo fator admitido como causa e consequência do processo de feminização do jornalismo português resulta do aumento dos níveis de habilitações académicas dos profissionais. Novamente no campo estrito dos detentores de título profissional, verifica-se um aumento de 3,3 por cento entre a proporção de profissionais com habilitações académicas em 2006 (Rebelo et al., 2011) e 2014.

Um cenário onde o recrutamento se desenvolve gradualmente entre licenciados e o corpo de formados é predominantemente feminino - uma comparação do género dos diplomados, entre 2000/01 e 2013/14, dos cursos de informação e jornalismo permite

3 Sem prejuízo de se vir a desenvolver esta questão, é particularmente paradigmático observar o quadro de evolução do contingente de jornalistas, que após um longo trajeto de, ainda que irregular, constante expansão, após meados dos anos 2000 conheceu uma inflexão no sentido de um decurso flutuante, mas do qual resulta uma erosão do número de jornalistas. Atendendo só ao conjunto de titulares de Carteira Profissional de Jornalista, esta evolução pode ser observada segundo os seguintes valores: 2006 -6767; 2009-6216; 2014 - 5608; 2016 - 5756 (primeiros dados disponíveis em Rebelo et al, 2011, e os segundos disponibilizados pela CCPJ).

4 Com exceção dos casos onde se alude especificamente aos dados relativos aos titulares de Carteira Profissional de Jornalista, todos os dados referentes ao universo dos jornalistas em 2014, aqui apresentados, compreendem o somatório dos detentores de Carteira Profissional de Jornalista, Título Provisório de Estagiário e Cartão de Identificação de Equiparado a Jornalista. 
encontrar um rácio médio de 2,7 mulheres por cada um homem que se diploma nestas áreas (INE, 2012; 2105) -, resultará, portanto, numa configuração sociográfica tendente a evidenciar as habilitações académicas dos segmentos femininos da profissão. Disso mesmo nos dão conta os dados da CCPJ (Figura 1), onde, não obstante uma ligeira variação relativamente ao grau de doutoramento, é sobretudo entre as mulheres jornalistas que se encontram os maiores níveis de habilitação académica. Destacam-se particularmente as diferenças, assentes num fator de género, relativas ao peso assumido pelos detentores de licenciatura e pelos jornalistas com formação de nível secundário.

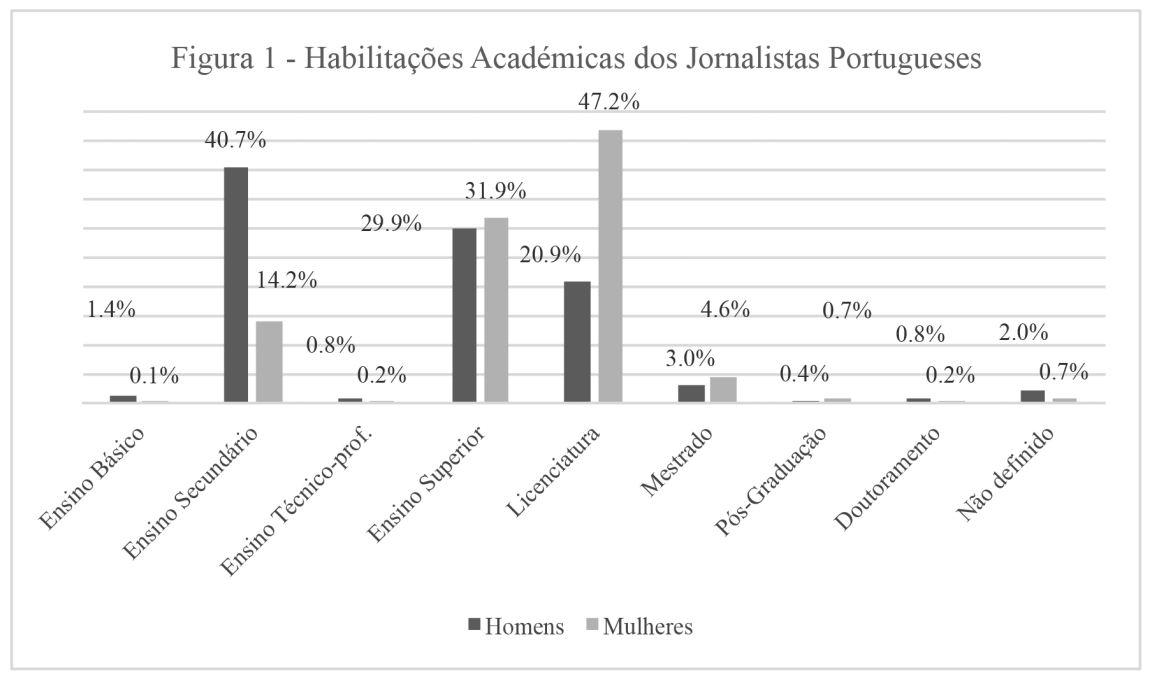

Fonte: Dados CCPJ (2014)

Reiterando a problemática inicial, importará, contudo, perceber que a atual conjuntura do jornalismo - marcada pelas dinâmicas concorrenciais da emergência de novos produtos digitais, esvaziamento das redações e novas fórmulas de trabalho - tenderá a abrandar, se não mesmo inverter, este quadro de tendências que têm delimitado 0 trajeto de recomposição do contexto socioprofissional do jornalismo português (Garcia et al., 2014). Como já se verificou, um dos traços mais evidentes desta transfiguração resulta na inflexão do irregular, mas permanente, alargamento do contingente dos jornalistas, que marcou sobretudo os anos 90 e 80, e que se traduziu, a partir de meados da década de 2000 , num quadro relativamente contínuo de decréscimo de profissionais. Esta é uma circunstância que se verifica tão mais relevante quando se observa que esta linha de abandono da profissão deixou de ser exclusiva dos setores mais envelhecidos, mas já inclui as franjas mais jovens - resultado de diferentes óbices no ingresso ou mesmo da desistência precoce dos recém-ingressados (Pacheco e Rebelo, 2014).

É neste sentido que, para lá da óbvia primordialidade de examinar prospetivamente os aspetos gerais deste processo de reconfiguração - sobretudo no que se refere a diferentes indícios de erosão do ethos e princípios do jornalismo, e à emergência de novos produtos informativos assentes numa matriz distinta de práticas e valores -, releva-se, pela ordem de razão de um contexto de acesso profissional progressivamente feminino, a necessidade de entender também o enquadramento 
das mulheres jornalistas, e das mulheres formadas em comunicação, nestas mesmas dinâmicas. Isto é, compreender as ameaças e oportunidades que se lhes colocam, mas também o seu papel enquanto agentes do progresso ou remissão desta conjuntura de alomorfia da produção de informação.

\section{"DoIs PASSOS ATRÁs"}

Apesar do efeito transformador que esta metamorfose do mercado do jornalismo possa vir a implicar num longo alcance, e de um abrandamento das dinâmicas reconfiguradoras da constituição do grupo profissional, os indicadores enunciados anteriormente revelam um contexto de recomposição sociográfica que pende para, no presente e num futuro próximo, dirimir e alternar a matriz de disparidade de género que pontuou todo o século XX. Este não é, porém, um processo exclusivamente português - um relatório recente do Global Media Monitoring Project (GMMP) (2015) demonstra como o crescimento do número de mulheres jornalistas assume, desde os anos 90, uma dimensão relativamente universal -, nem decorre apenas dos fatores mencionados anteriormente. Se, como referem Tusan (2005) ou Steiner (2009), esta recomposição se inscreve num percurso histórico mais vasto da luta feminina pelo acesso a uma esfera de autoridade e influência institucional, concernirá também atender aos argumentos de, por exemplo, Aldridge (1998), Diament (ApudWaisbord, 2000) ou Oliver (2014), que estabelecem uma relação entre este movimento de recrutamento de mulheres jornalistas e um quadro velado de estratégias comerciais ou administrativas. Esta conceção paradoxal é reflexo da realidade contraditória da inserção das mulheres jornalistas nas redações: conquanto se constituam um elemento fundamental e em expansão no atual enquadramento da produção jornalística, a posição das mulheres nesse contexto é ainda profundamente relativizada em diferentes dimensões da atividade. É neste sentido que Fröhlich (2007: 174) considera mesmo a feminização do jornalismo como um "mito": "enquanto deram três passos em frente durante os anos 80, as mulheres jornalistas de todo o mundo recuaram dois passos a partir de meados dos anos 90".

Um dos aspetos em que esta relativização permanece mais óbvia manifesta-se na assimetria axiomática da presença de mulheres nos cargos de chefia e responsabilidade editorial. Novamente, o parecer do GMMP (2015), mas também 0 levantamento da Women's Media Center (2015), apresenta esta como uma realidade global - mas que tende a assumir caraterísticas relativamente idênticas nos diferentes países. De resto, reportando-se ao contexto norte-americano, Lipinski (2014: 2) resume, num dos últimos Neiman Reports, uma realidade que, à luz dos indicadores anteriormente observados, facilmente poderia caraterizar a situação portuguesa: "as mulheres não ascendem aos lugares de topo de qualquer um dos setores dos media a um ritmo sequer idêntico àquele que carateriza a sua entrada nas escolas de jornalismo". Com efeito, diferentes levantamentos realizados em Portugal - a título de exemplo, Salim (2008), Subtil (2009) e Miranda (2014) - revelam que esta discrepância entre os níveis de presença das mulheres nas redações e a sua participação nos cargos de responsabilidade editorial tem pautado todo 0 decurso contemporâneo do jornalismo português - um fenómeno que se expande, inclusivamente, às esferas de decisão da organização profissional e da regulação ${ }^{5}$.

5 Releva-se, no entanto, o facto de, no momento em que este texto é escrito, os cargos de pre- 
Ran (2015: 43) faz notar que este quadro de falta de representação das mulheres jornalistas deve ser observado segundo uma perspetiva mais ampla do que apenas a dimensão da sua presença nos cargos de chefia editorial. Esta fraca reflexão da recomposição das redações está também presente numa assimetria das tarefas e responsabilidades, onde as estatísticas demonstram que as mulheres "não são encaradas com confiança nem respeito para contar as histórias, para analisar os eventos e para transmitir os principais assuntos às audiências e leitores"6.

Uma terceira ameaça ao processo de feminização do jornalismo resulta do conjunto das condições laborais em que esse decurso ocorre. Num contexto de reenquadramento do mercado - motivado pela eclosão de uma conjunção paralela de produtos digitais e pela progressiva financeirização da informação -, 0 jornalismo pende, por um lado, para ser vítima dessas mesmas dinâmicas e, por outro, para se reorientar no sentido de lógicas mais coincidentes com pressupostos comerciais. Reproduzem-se assim, estratégias de moderação de despesas, reformatação da oferta jornalística e redução de custos com pessoal (Mosco, 2009; Meyer, 2009; Siapera, 2013). A par de um encerramento massivo e contínuo de títulos ${ }^{7}$, em Portugal, os diferentes dados disponibilizados pelo Sindicato dos Jornalistas, Caixa de Previdência e CPPJ indiciam a proliferação de situações de despedimento, baixos índices salariais e substituição de vínculos laborais permanentes por fórmulas de contrato mais instáveis, onde se pautam os falsos recibos verdes e as práticas contínuas de estágios profissionais e extracurriculares não remunerados (Graça, 2009; Baptista, 2012; Bastos, 2014; Pacheco, e Freitas, 2014). Se é entre os segmentos mais jovens da profissão, e logo mais feminizados, que estes fenómenos de precarização mais se fazem incidir, depreende-se, portanto, que este quadro tenderá a afetar sobretudo os conjuntos femininos da profissão.

Conquanto não existam ainda estudos recentes que permitam compreender 0 impacto destas políticas sobre os processos de feminização das redações portuguesas, os diferentes relatórios, já aqui mencionados (GMMP, 2015; WMC, 2015),

sidência do Sindicato dos Jornalistas e do Conselho Deontológico serem ambos ocupados por muIheres. Ainda que, em mais de 80 de história, sejam respetivamente a segunda e terceira mulheres jornalistas a ocupar os cargos.

6 De Bruin e Ross (2004) referem que boa parte dos primeiros estudos feministas focados na questão da entrada das mulheres nas redações alimentaram a premissa que relaciona 0 acesso dos segmentos femininos da profissão aos quadros de responsabilidade editorial e um quadro de influência no sentido da reformatação das temáticas e agendas noticiosas. Conquanto não se pretenda neste estudo aprofundar esta discussão, importará mencionar a confrontação que, por exemplo, Kitch (2015) desenvolve entre os resultados de diferentes estudos, onde se verificam orientações distintas relativamente a este pressuposto teórico. Também Linda Steiner (2012) debate esta problemática num artigo crítico sobre o campo teórico debruçado a entender as diferenças de género no jornalismo. NeiVER HEMMINGS, C., e HENRY, M., NRY, M.limso.açopo o as nados, ondiçunçr as disparidade açdem o somat0 anos.r/rep chefia editoAinda interligado com as questões aqui desenvolvidas, importará observar no artigo de Steiner o quadro de hipóteses avançado referente a explicar a fraca representação de mulheres nos cargos de topo do jornalismo.

7 Por exemplo, uma análise aos relatórios de atividades e contas do Instituto da Comunicação Social e Entidade Reguladora para a Comunicação Social permite perceber que, desde 2003, o número de registos de cancelamento de empresas e títulos de comunicação tem permanentemente superado o número de registos de inscrição. 
referentes a geografias distintas, denotam uma disparidade de género inerente aos efeitos da erosão da segurança e condições laborais, onde estabilidade dos vínculos, desrespeito pelas convenções laborais e, sobretudo, desequilíbrio da relação salarial pendem a ser a particularmente críticos entre os segmentos femininos da profissão.

É sobretudo a partir deste quadro de reorganização e constrangimentos que se procurará desenvolver a demonstração de tendências do contexto socioprofissional do jornalismo português e da sua relação com os aspetos do processo de feminização.

\section{DESCRIÇÃO METOdOLÓGICA DO INQUÉRITO A JORNALISTAS}

Os dados apresentados e discutidos ao longo desta análise derivam dos resultados obtidos num inquérito aplicado ao universo dos titulares de Carteira Profissional de Jornalista, Título Provisório de Estagiário e Cartão de Identificação de Equiparado a Jornalista. Aplicado, entre dezembro de 2014 e fevereiro de 2015, por via online - com recurso à plataforma LimeSurvey - entre os contactos de correio eletrónico detidos pela CCPJ, o inquérito conheceu um total de 1066 respostas $^{8}$. Por motivos de incompletude do questionário, foram excluídas 260 respostas, obtendo-se desta forma um resultado final de 806 respostas admitidas. A aplicação de um teste de qui-quadrado entre os dados obtidos e os dados do universo, nos campos disponíveis pelos registos da CCPJ, revelou a inexistência de diferenças estatisticamente significativas entre a amostra e a população.

0 questionário base deste inquérito é composto por cinco grupos de questões ${ }^{9}$ e 90 perguntas principais.

Este inquérito insere-se numa linha relativamente ampla de estudos onde se incluem, a título de exemplo, os I e II Inquéritos Nacionais aos Jornalistas, bem como uma série de inquirições aos jornalistas desenvolvidas já no século XXI: Lima (2010), Miranda (2012), Cardoso et al. (2012) ou Rebelo et al. (2014). Porém, a falta de atualidade dos resultados dos primeiros estudos e a especificidade da amostra ou das questões das segundas investigações, combinada com a parca diversificação dos dados detidos pela CCPJ, constituíram-se alguns dos motivos centrais que fundamentaram a realização do presente estudo

Importa notar que o inquérito aqui apresentado foi desenvolvido no âmbito do trabalho de uma tese de doutoramento centrada nos desafios que se colocam ao jornalismo contemporâneo, com ênfase na proposta de novos modelos de autorregulação profissional. Assim, conquanto tenha também sido desenvolvido com o intuito de caraterizar a realidade socioprofissional do jornalismo português, este inquérito não partiu do propósito central de pormenorizar as dinâmicas que constituem o processo de feminização do jornalismo português. Contudo, a partir da desagregação por género dos resultados obtidos, referentes às condições de trabalho, rotinas e expetativas dos jornalistas, pretende-se emprestar um contributo para um aprofundamento deste exercício de caraterização. A representação da amostra em termos de género compreende 58,7 por cento de homens e 41,3 por cento de mulheres.

8 Compete referir que do total de e-mails enviados, com a referência ao inquérito, 210 falharam a chegada ao seu destinatário.

9 "Dados sociográficos", "Remuneração e situação profissional", "Caraterização das rotinas produtivas", "Expetativas e atitudes" "Meios de regulação". 
Perante um contexto onde, como o demonstram os dados da CCPJ, se relevam, em termos de género e idade, dois segmentos distintos - um mais envelhecido e masculino, e outro mais jovem e feminino -, à medida que se avançava na presente análise, surgiu a interrogação se as tendências desvendadas não obedeceriam mais a uma condição de idade/antiguidade profissional do que a um fator de género. Assim, procedeu-se a um cruzamento entre os indicadores demonstrados à frente $\mathrm{e}$ os fatores idade e antiguidade profissional. Concomitantemente, procurou-se analisar o mesmo quadro de tendências dentro de duas amostras: uma reduzida aos inquiridos com menos de 40 anos e outra reduzida aos inquiridos com até 15 anos de atividade. Resultou, no entanto, óbvio que as tendências evidenciadas derivam sobretudo de aspetos relacionados com fatores de género.

\section{Demonstração de tendênCias}

Partindo deste exercício de decomposição dos resultados, uma das principais inferências que, desde logo, se sobreleva, resulta numa disposição de certo modo transversal para uma simetria de respostas, com especial incidência entre as problemáticas das rotinas produtivas e da autorrepresentação dos valores profissionais. Evidenciam-se, contudo, relativos níveis de disparidade na perceção dos homens e mulheres inquiridos relativamente os campos de contradição anteriormente aludidos, onde se destaca autoconceção da situação laboral e autonomia profissional, perceções sobre os modos de acesso à atividade ou condições de trabalho.

De facto, um dos fatores essenciais do processo de recomposição de género do quadro profissional do jornalismo, enunciado anteriormente, prende-se com a sua inexpressiva representação nas esferas de responsabilidade e chefia editorial. A desagregação por género do enquadramento dos inquiridos em termos do estatuto profissional assumido (Figura 2) revela um cenário que pende para identificar esses mesmos pressupostos de assimetria.

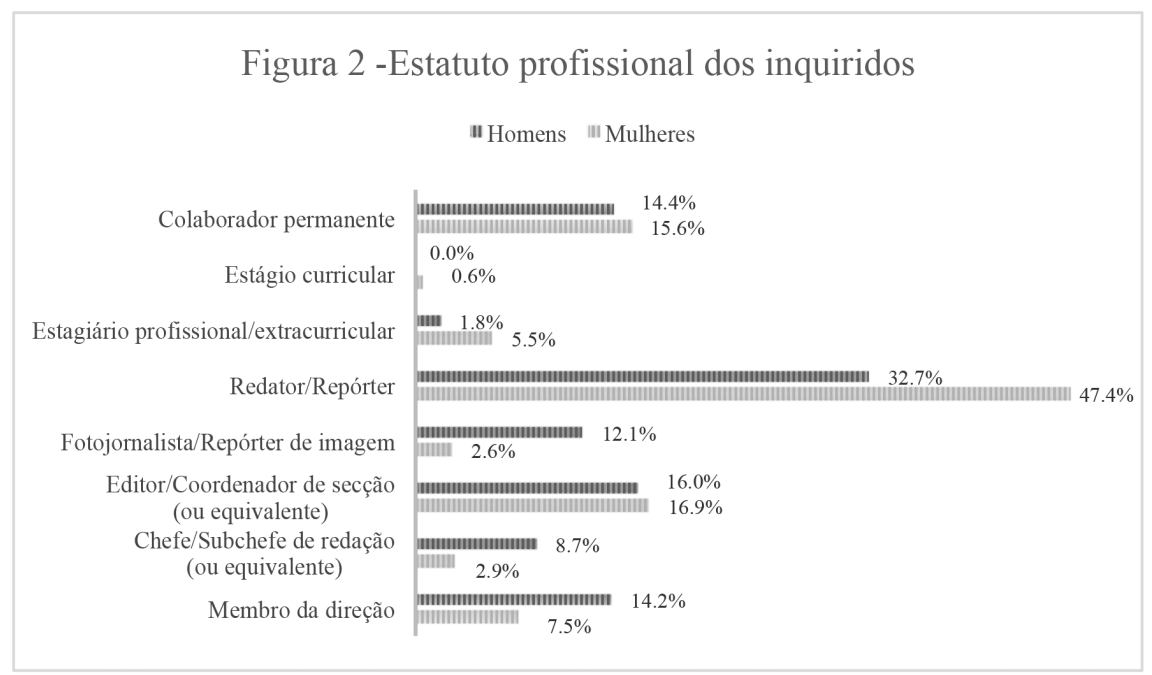

Fonte: Inquérito aos Jornalistas Portugueses (nov. 2014 - fev. 2015) 
Ainda que seja possível reconhecer uma exígua variação conducente a favorecer a representação das mulheres jornalistas nas posições de chefia de edição, torna-se evidente, nesta amostra, a preponderância masculina entre os postos executivos editoriais - dos respondentes com cargos de chefia e direção de redação, 68.8 por cento são homens. Concerne ainda observar o peso assumido pelos elementos do sexo feminino entre os postos de executante, sobretudo entre os cargos de redator/repórter, onde a variação entre mulheres e homens inquiridos com funções de redator/repórter é de 18,4 por cento.

0 quadro estatístico mencionado por Ran (2015) refere que a dimensão da assimetria de género atinge também o plano das tarefas e responsabilidades das muIheres jornalistas. Tomando como referência os indicadores do inquérito relativos às práticas profissionais - sobretudo vinculados às problemáticas da proletarização e desprofissionalização do jornalismo - não se verificam discrepâncias particulares no que concerne ao âmbito da responsabilização e participação na vida editorial, embora se observe uma propensão, ainda que bastante tangencial, para ser entre o segmento feminino da profissão que mais se evidenciam práticas burocratizadas.

Com efeito, dos 82,2 por cento de inquiridos que admite ver entre "frequentemente" e "sempre" 10 os seus trabalhos assinados, a variação entre homens e muIheres é apenas de 1,5 por cento. Em sentido idêntico, entre os 91,6 por cento de inquiridos que referem ter entre "frequentemente" a "sempre" aceites as suas propostas para tratar uma matéria, a distância entre uma posição dominante das muIheres e a dos homens é de 2,9 por cento - variação que se inverte quando se refere apenas ao caso "sempre". Também a variação de género entre os 90,8 por cento de respondentes que mencionam "Nunca" ou "Raramente" ter visto o seu trabalho modificado sem a sua autorização é de um por cento.

No que se refere ao contexto das rotinas produtivas adotadas, a situação de correspondência pende a manter-se. A diferença de género entre os inquiridos que admitem entre "frequentemente" e "sempre" contactar pessoalmente com as fontes é quase nula - 87,3 por cento de homens e 85,5 por cento de mulheres - e o mesmo se verifica relativamente ao recurso exclusivo a notas de imprensa na redação ou produção de notícias: 58,7 por cento de homens e 59,7 por cento de mulheres refere "nunca" ou "raramente" fazê-lo. Ainda que numa expressão muito ténue, é possível identificar alguma disparidade relativamente à burocratização das práticas no facto de 27,9 por cento das mulheres inquiridas mencionar "nunca" ou "raramente" abandonar a redação no tratamento das matérias - apenas 21,2 por cento dos homens admite isso - e nos 21,7 por cento de mulheres - e 17,9 por cento de homens - que refere produzir mais de sete peças por edição.

Uma questão do inquérito pedia aos jornalistas que ordenassem, dentro de seis possibilidades, uma hierarquia de metodologias utilizadas no contacto com as fontes. É sobretudo neste campo que se evidenciam as maiores discrepâncias relativamente às práticas, com 70 por cento das mulheres a admitir como metodologia privilegiada práticas que não compreendem o contacto presencial com as fontes - um valor que se situa nos 59 por cento das respostas de homens. A eleição de

10 Numa escala que atravessa os níveis "Nunca", "Raramente", "Frequentemente", "Muitas vezes" e "Sempre". 
modelos de articulação com as fontes assentes na via telefónica não é compensada, do ponto de vista do contacto presencial, na segunda escolha de metodologias, onde o diálogo face-a-face assume uma expressão de 15,2 por cento entre as mulheres e 14,8 por cento entre os homens.

Assim, com a devida exceção deste último paradigma, relativo aos modelos de contacto com as fontes, os resultados obtidos não indiciam assimetrias singulares entre as condições de responsabilização e práticas em que os homens e mulheres inquiridos desenvolvem a sua atividade. Sugere-se, desta forma, uma transversalidade concernente ao género do quadro de proletarização e burocratização das rotinas produtivas dos jornalistas.

Um último aspeto evocado relativamente aos modos em que se vem operando 0 processo de feminização das redações debate-se com as condições socio-laborais em que essa reconfiguração profissional ocorre.

No âmbito da análise sobre a forma como as circunstâncias que moldam o trabalho dos jornalistas influem na relação de género da atividade, a problemática da relação salarial assume, como já se relevou, especial pertinência. Neste campo, as respostas dos inquiridos revelam dados particularmente críticos, quando apenas um quarto destes admite auferir uma remuneração mensal ilíquida média acima dos 1500 euros, a maioria recebe um salário bruto abaixo dos 1000 euros e 14,8 por cento responde não receber qualquer remuneração ${ }^{11}$ ou auferir valores abaixo do então Salário Mínimo Nacional.

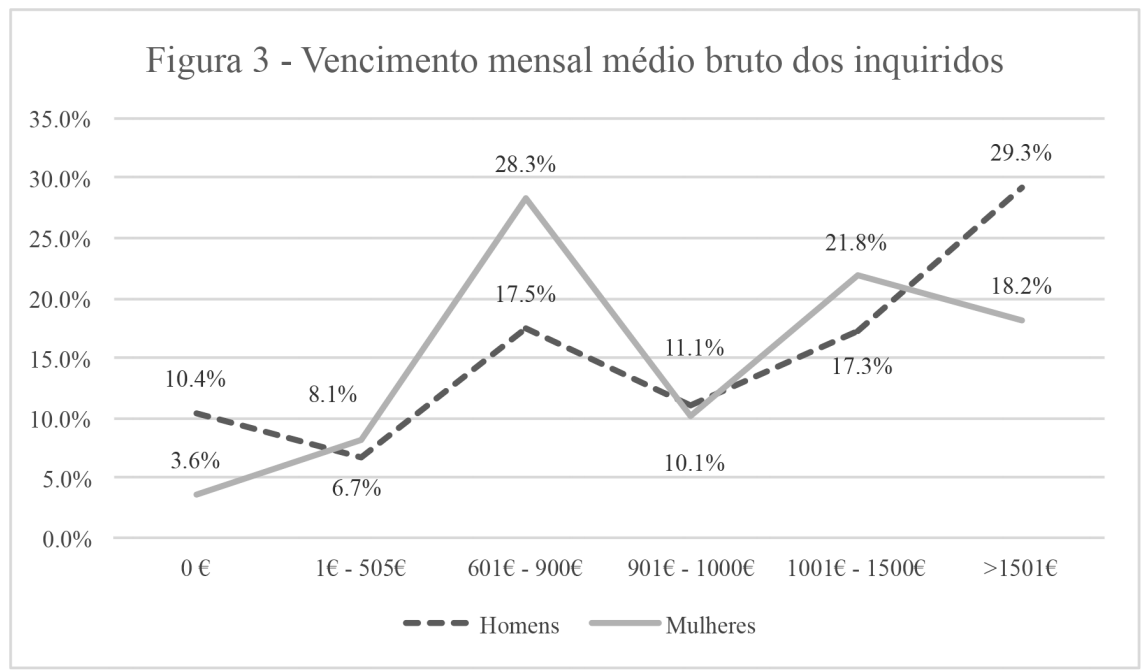

Fonte: Inquérito aos Jornalistas Portugueses (nov. 2014 - fev. 2015)

11 A questão do trabalho sem retorno financeiro suscitou particulares interrogações, sobretudo interligadas com a possibilidade de se reportar a circunstâncias de atividade voluntária. Assim, procedeu-se a um cruzamento entre o fator salarial e o indicador do título profissional assumido - colocando-se como hipótese os casos mencionados constituírem-se atividade de portadores de Cartão de Identificação de Equiparado a Jornalista, isto é, diretores de órgãos de informação que assumem o jornalismo como atividade secundária - segmento constituído predominantemente por homens. Constatou-se, porém, que esta parcela de inquiridos sem remuneração se refere sobretudo a detentores de título profissional. 
A desagregação por género desses índices remuneratórios permite identificar que é sobretudo nos estratos cêntricos que as mulheres inquiridas se situam - com especial relevância para os segmentos entre os 601 e os 900, e os 1001 e os 1500 euros. No âmbito deste estudo, é particularmente pertinente notar a disparidade explícita nos estratos relativos aos índices salariais mais elevados, corroborando, de alguma forma, estes resultados a conceção de desequilíbrio de género assente numa diferença salarial.

0 contexto assimétrico da relação entre género e índices remuneratórios destes jornalistas não possui, contudo, reflexo no vínculo laboral assumido pelos inquiridos. 0 que nos demonstra a Figura 4 é um quadro de relativo paralelismo, onde, sem prejuízo de uma ligeira discrepância entre os contratados mediante esquemas de estágio profissional ou prestação de serviços, ambos jornalistas homens e muIheres tendem a enquadrar-se nas mesmas lógicas de vínculo laboral.

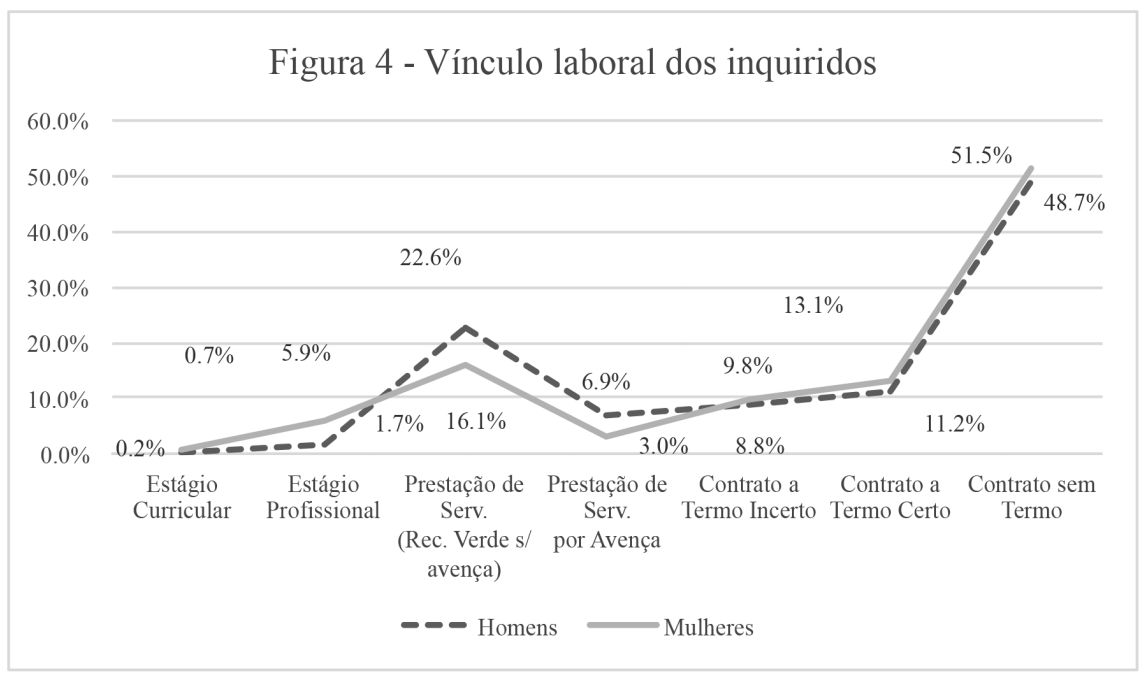

Fonte: Inquérito aos Jornalistas Portugueses (nov. 2014 - fev. 2015)

A ligeira variação relativa à inserção em lógicas de empregabilidade relacionadas com 0 estágio profissional pode, ainda assim, ser explicada segundo o cruzamento de uma conjuntura de acesso à profissão predominantemente feminina e da perceção do estágio profissional enquanto estratégia de ingresso, ou reingresso ${ }^{12}$, no jornalismo. A atividade integrada nestes modelos de vínculo deve, contudo, ser observada à luz do âmbito de extrema precariedade em que se inserta. Para lá da fragilidade do próprio vínculo, como o demonstram os resultados do presente inquérito, a atividade inserida em lógicas de estágio profissional incide em níveis remuneratórios bastante baixos ou mesmo nulos.

A problemática dos estágios profissionais e extracurriculares, enquanto estratégia de acesso à profissão, mas também como modelo de reconfiguração dos vínculos

1256 por cento dos inquiridos inseridos nesta lógica de vínculo admite já ter desenvolvido atividade em outros órgãos de comunicação social (OCS) - 20 por cento em mais do que dois OCS - e uma margem diminuta refere mesmo já se ter visto envolvido em situações de despedimento. 
laborais no sentido da sua instabilidade, adota especial significado no contexto da presente análise, uma vez que é a partir desta dinâmica que se manifesta uma das mais relevantes marcas de disparidade de género no âmbito do trabalho dos jornalistas. Se 36,5 por cento dos homens inquiridos refere já ter realizado um estágio extracurricular não remunerado, este fenómeno assume uma expressão de 48,3 por cento entre as mulheres ${ }^{13}$. Este cenário de desequilíbrio é ainda projetado para 0 plano de expetativas que fundamentam essa escolha (Figura 5), sendo sobretudo as mulheres que perspetivam o período de atividade não remunerada como meio de acesso à profissão.

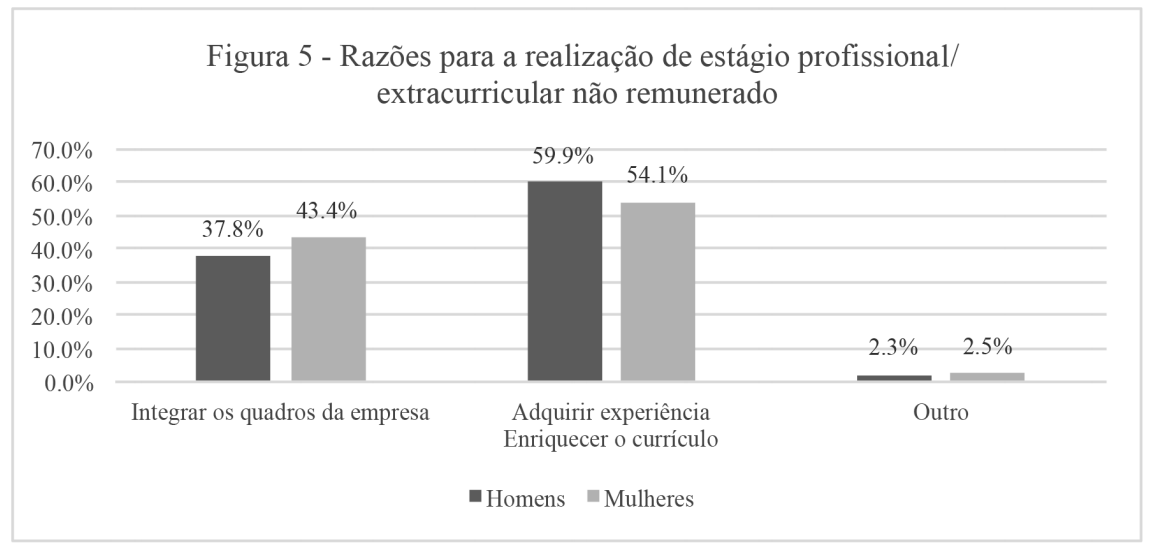

Fonte: Inquérito aos Jornalistas Portugueses (nov. 2014 - fev. 2015)

Procurando cruzar as dimensões das rotinas produtivas e das condições de trabalho, não se observa particular discrepância entre os 64,2 por cento de inquiridos que referem desenvolver tarefas extraordinárias às que têm contratualizadas - a variação é de 3,3 por cento - e, entre os respondentes que mencionam ver os seus trabalhos transpostos para outros OCS do mesmo grupo empresarial, 56,1 por cento correspondem a homens e 47,2 por cento a mulheres. Contudo, quando inquiridos sobre a remuneração dessas mesmas práticas, apenas 10,7 por cento dos homens e 6,8 por cento das mulheres refere auferir uma retribuição suplementar pela transposição dos conteúdos. E, se 17,2 por cento dos homens jornalistas que desempenham funções extraordinárias são compensados monetariamente por isso, entre as mulheres, a retribuição assume uma expressão exígua de 9,2 por cento ${ }^{14}$.

13 Reportando-se esta problemática específica a um contexto relativamente contemporâneo, uma das explicações naturais para esta discrepância de respostas poderá residir nos fatores idade ou antiguidade profissional. Reduzindo este quadro de análise à amostra dos inquiridos com menos de 40 verifica-se efetivamente uma contração da disparidade, mantendo-se, contudo, entre as mulheres o maior nível de frequência de estágios não remunerados - 50,3\%/50,9\% - uma variação bastante idêntica à observada numa amostra confinada aos inquiridos com até 15 anos de atividade.

14 Outros critérios referentes ao quadro laboral e a sua relação com as práticas, como o envolvimento em situações de despedimento ou a modificação do trabalho sem autorização dos profissionais demonstram variações marginais. Já aspetos como o desenvolvimento de atividade em OCS exteriores à empresa com que detêm o contrato principal ou o desenvolvimento de outra atividade que não 
Retomando a problemática dos estágios não remunerados e a incidência que assume entre 0 conjunto das mulheres jornalistas, outra das explicações poderá residir no facto de, como o demonstram os dados da CCPJ e INE já enunciados, tanto a constituição dos cursos de jornalismo como dos estratos profissionais com formação superior ser eminentemente feminina. Poderá também residir neste aspeto a assimetria patente no campo das conceções sobre os modelos que devem orientar 0 acesso à profissão. Se entre os 85,4 por cento de inquiridos que concordam com a obrigatoriedade do estágio para 0 acesso ao exercício do jornalismo a variação entre mulheres e homens é de apenas 1,5 por cento, é entrando no campo das perceções sobre a relação entre a substancialidade da detenção de graus específicos e 0 acesso à profissão que se revelam diferentes dimensões de entendimento, sendo entre as mulheres que mais se patenteia a valorização da habilitação académica enquanto elemento imprescindível para o exercício do jornalismo. Com efeito, enquanto 56,3 por cento dos homens concordam com a indispensabilidade de uma formação superior para 0 acesso à profissão, entre as mulheres esta expressão assume 0 s 76,2 por cento. Coincidentemente, se 45,6 por cento das mulheres inquiridas consideram que essa formação deve ser especializada nas áreas de jornalismo, apenas 34,6 por cento dos homens concorda com essa ideia ${ }^{15}$.

Ainda sobre 0 âmbito das conceções, finalmente, interessará observar de que forma a questão de género pode ou não influir nas perceções sobre as condições de trabalho e autorrepresentação profissional. É, de facto, quando se reportam às condições e níveis autonomia que mais se evidenciam discrepâncias. A título de exemplo, entre os inquiridos que garante cumprir "sempre" os preceitos ético-deontológicos a variação de género é de apenas 0,2 por cento. Mas, quando se referindo à perceção sobre a sua situação laboral afetar o desempenho do seu trabalho, a percentagem de homens que referem "concordar " ou "concordar totalmente"16 é de 53,1, expressão que sobe 57 por cento entre as mulheres.

Relativamente às condições de autonomia, este desequilíbrio de opiniões é ainda mais marcado. Se a segurança da possibilidade de trabalho se oferece como condição imprescindível no domínio da autonomia profissional, concerne observar que, perante uma situação de desemprego, 34,4 por cento dos homens responde" discordar totalmente" da ideia de que facilmente encontraria um novo emprego na área do jornalismo. Concerne ainda mais observar que esta cifra é de 48,4 por cento entre as mulheres. Isto implica, claro está, uma circunstância de limitação da liberdade na atividade. Circunstância essa que é bem patente na distância verificada relativamente à posição dos inquiridos sobre a ideia de possuírem total liberdade na produção de conteúdos: 35,7 por cento dos homens inquiridos "concorda totalmente" com a ideia. Entre as mulheres, esta conceção assume uma expressão de apenas 22,7 por cento.

o jornalismo verifica-se ocorrer sobretudo entre os homens, com uma variação de 6,2\% relativamente ao primeiro e $5,8 \%$ sobre 0 segundo.

15 Um cruzamento entre estes dois indicadores e o fator idade revela alguma distribuição transversal das respostas, pelo que se deduz que a disparidade de conceções assenta mais num elemento de género do que num elemento etário.

16 Numa escala que atravessa os níveis "Concorda totalmente", “Concorda”, “Não concorda nem discorda", "Discorda" e "Discorda totalmente". 
Este estudo procurou enquadrar o contexto recente e contemporâneo da recomposição de género das redações portuguesas segundo dois paradigmas distintos. 0 primeiro centra-se num constante processo de feminização do corpo profissional, alicerçado num rejuvenescimento dos quadros e num contínuo aumento da formação. Com efeito, a análise da evolução dos dados sobre 0 universo dos jornalistas evidencia um trajeto que tende a dirimir o desequilíbrio, assente no género, da composição das redações. Ao mesmo tempo, acentuam-se também maiores níveis de habilitações académicas, sobretudo entre os setores femininos da profissão. Diferentes fatores, onde se releva a já patente erosão do contingente de jornalistas, indiciam um cenário onde o efeito transformador destas dinâmicas será abrandado ou invertido.

0 segundo paradigma reporta-se a um conjunto de contradições inerentes a este processo de feminização, onde se pauta um fraco acesso das mulheres jornalistas a cargos e funções de responsabilidade editorial, e uma assimetria no campo das condições de trabalho. A desagregação por género dos resultados do inquérito aos jornalistas portugueses demonstra que, não obstante uma tendência geral para uma relativa harmonia entre as respostas de homens e mulheres, se evidenciam algumas discrepâncias relativas à situação laboral e ao campo das conceções sobre o exercício da profissão.

Apesar de uma já assinalável profusão de estudos focados em situações concretas ou em histórias individualizadas, e não obstante o contributo dos diferentes estudos aqui referidos, o aprofundamento do papel e situação das mulheres no quadro da transformação socioprofissional do jornalismo, e da comunicação, encontra-se ainda pouco problematizado. A realidade desenvolvida neste estudo pretende também oferecer pistas de análise futura sobre estas questões, onde, não só o conjunto de tendências manifestadas pelo exercício de desagregação dos resultados do inquérito, mas também o quadro de alteração das tendências de recomposição profissional e o enquadramento das jornalistas no processo de transfiguração do mercado de informação resultam pontos cardeais fundamentais de investigação.

\section{Bibliografia}

ALDRIDGE, M. (1998). The tentative hell-raisers: identity and mythology in contemporary UK press journalism, Media, Culture \& Society, 20(1), 109-127.

BAPTISTA, C. (2012), Uma profissão em risco iminente de ser "descontinuada, Jornalismo \& Jornalistas, 52, 15-17.

BASTOS, H. (2014). Da crise dos media ao desemprego no jornalismo em Portugal, Parágrafo: Revista Científica de Comunicação Social da FIAM-FAAM, 2(2), 38-46.

DE BRUIN, M. e ROSS, K. (2004), Gender and Newsroom Cultures: Identities at Work, Cresskill, NJ: Hampton Press.

FRÖHLICH, R. (2007), Three steps forward and two back?: women journalists in the western world between progress, standstill, and retreat. In Women in mass communication, eds. CREEDON, P. J. e CRAME, J., Thousand Oaks, CA: SAGE Publications Ltd, 161-176.

GARCIA, J. L. (2009), Principais tendências de profissionalização dos jornalistas no período pós-transição democrática. In Estudos Sobre os Jornalistas Portugueses: Metamorfoses e encruzilhadas no limiar do século XXI, ed. GARCIA, J. L., Lisboa: ICS - Imprensa de Ciências Sociais, 63-92. 
GARCIA, J. L., MARMELEIRA, J., e MATOS, J. N. (2014). Incertezas, vulnerabilidades e desdobramento de atividades. In As novas gerações de jornalistas portugueses, ed. REBELO, J. Lisboa: Mundos Sociais. 9-19.

GMMP (Global Media Monitoring Project) (2015), Who Makes the News?, Toronto e Londres: World Association for Christian Communication (WACC).

GRAÇA, S. M. (2009), Os problemas-chave de ingresso no jornalismo. In Estudos Sobre os Jornalistas Portugueses: Metamorfoses e encruzilhadas no limiar do século XXI, ed. GARCIA, J. L., Lisboa: ICS - Imprensa de Ciências Sociais, 133-168.

KITCH, L. (2012), Women in the Newsroom: Status and Stasis, Journalism \& Mass Communication Quarterly, 92(1), 35-38.

Lipinski, A. M. (2014). A seat at the table. Neiman Reports, 68(3), 2-3.

MEYER, P. (2009), The Vanishing Newspaper: Saving journalism in the information age. Columbia: University of Missouri Press.

MIRANDA, J. (2014), Notas sobre o papel e a situação da mulher no processo de profissionalização do jornalismo português e no decurso da desregulação profissional, Media \& Jornalismo, 25, 54-74.

MOSCO, V. (2009), The Political Economy of Communication, Londres: SAGE Publications Ltd. OLIVER, H. (2014). 'It's all about shopping': The role of consumption in the feminization of journalism. In The SAGE handbook of feminist theory, eds. EVANS, M., HEMMINGS, C., e HENRY, M., Londres: SAGE, 251-266.

PACHECO, L., e FREITAS, H. S. (2014). Poucas expectativas, algumas desistências e muitas incertezas. In As novas gerações de jornalistas portugueses, ed. REBELO, J. Lisboa: Mundos Sociais. 21-36.

PACHECO, L., e REBELO, J. (2014), The predicament of Young Journalists: The study of Portugal, OBS* 8(2), 83-109.

RAN, M. (2015), Pushing Back: GMMP results. In Who Makes the News?, ed. GMMP, Toronto e Londres: World Association for Christian Communication (WACC), 60.

REBELO, J. (org.)(2011), Ser Jornalista: Perfil Sociológico do Jornalista Português, Lisboa: Gradiva.

SALIM, I. (2008), A "Feminização" do Jornalismo em Portugal, Trajectos, 12, 117-124.

STEINER L (2009), Gender in the newsroom. In Handbook of Journalism Studies, eds. WAHLJORGENSEN K, HANITZSCH T. Londres: Routledge, 116-129.

STEINER, C. (2015), Failed Theories: Explaining Gender Difference in Journalism, Review of Communication, 12(3), 201-223.

SUBTIL, F. (2009), Anotações sobre o processo de feminização da profissão de jornalista na década de 1990. In Estudos Sobre os Jornalistas Portugueses: Metamorfoses e encruzi- Ihadas no limiar do século XXI, ed. GARCIA, J L., Lisboa: ICS - Imprensa de Ciências Sociais, 93-108.

TUSAN, M. (2005), Women Making News: Gender and Journalism in Modern Britain. Urbana e Chicago: University of Illinois Press.

WAISBORD, S. (2000). Watchdog journalism in South America. Nova lorque: Columbia University Press.

WMC (Women's Media Center) (2015), The Status of Women in the U.S. Media 2015. Nova Iorque: Women's Media Center. 
João Miranda - É investigador do Centro de Estudos Interdisciplinares do Século XX, encontrando-se a concluir a tese de doutoramento sobre o espaço e realidade da autorregulação profissional do jornalismo português no contexto europeu. É também professor assistente convidado na Faculdade de Letras da Universidade de Coimbra.

Data de recepção do artigo/ Received for publication: 03.01.2017

Data de aceitação do artigo/ Accepted in revised form: 20.02.2017 